\title{
Prevention and Management of Cerebral Small Vessel Disease
}

\author{
Vincent Mok, Jong S. Kim ${ }^{\mathrm{b}}$ \\ ${ }^{a}$ Division of Neurology, Department of Medicine and Therapeutics, Prince of Wales Hospital, The Chinese University of Hong Kong, Hong Kong Special \\ Administrative Region, China

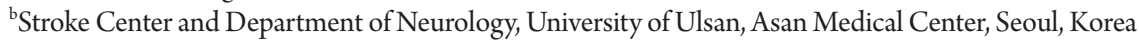

Lacunar infarcts/lacunes, white matter hyperintensities (WMH), and cerebral microbleeds (CMBs) are considered various manifestations of cerebral small vessel disease (SVD). Since the exact mechanisms of these manifestations differ, their associated risk factors differ. High blood pressure is the most consistent risk factor for all of these manifestations. However, a "J curve" phenomenon in terms of blood pressure probably exists for WMH. The association between cholesterol levels and lacunar infarcts/lacunes or WMH was less consistent and sometimes conflicting; a low cholesterol level probably increases the risk of CMBs. Homocysteinemia appears to be associated with WMH. It is noteworthy that the risk factors profile may also differ between different lacunar patterns and CMBs located at different parts of the brain. Thrombolysis, antihypertensives, and statins are used to treat patients with symptomatic lacunar infarction, just as in those with other stroke subtypes. However, it should be remembered that bleeding risks increase in patients with extensive WMH and CMBs after thrombolysis therapy. According to the Secondary Prevention of Small Subcortical Strokes trial results, a blood pressure reduction to $<130 \mathrm{mmHg}$ is recommended in patients with symptomatic lacunar infarction. However, an excessive blood pressure decrease may induce cognitive decline in older patients with extensive WMH. Dual antiplatelet therapy (aspirin plus clopidogrel) should be avoided because of the excessive risk of intracerebral hemorrhage. Although no particular antiplatelet is recommended, drugs such as cilostazol or triflusal may have advantages for patients with SVD since they are associated with less frequent bleeding complications than aspirin.

Keywords Prevention; Treatment; Small vessel disease

\author{
Correspondence: Jong S. Kim \\ Department of Neurology, Asan Medical \\ Center, University of Ulsan College of \\ Medicine, 88 Olympic-ro 43-gil, \\ Songpa-gu, Seoul 138-736, Korea \\ Tel: +82-2-3010-3440 \\ Fax: +82-2-474-4691 \\ E-mail: jongskim@amc.seoul.kr
}

Received: February 22, 2015

Revised: April 7, 2015

Accepted: April 7, 2015

Supported by a grant from Ministry for Health, Welfare and Family Affairs, Republic of Korea (HI14C1985).

The authors have no financial conflicts of interest.

\section{Introduction}

Lacunar infarcts (lacunes), white matter hyperintensities $(\mathrm{WMH})$, and cerebral microbleeds (CMBs) are considered various manifestations of cerebral small vessel disease (SVD). These lesions are associated with a plethora of disabilities (e.g., stroke, cognitive impairment, depression, gait disturbances, urinary symptoms) ${ }^{1,2}$ Given its close association with vascular risk fac- tors, the disabilities and mortality associated with these lesions are potentially preventable. Here we review the risk factors and management of cerebral SVD.

\section{Lacunar infarcts / lacunes}

In this review, lacunar infarct refers to a small subcortical ischemic lesion presumably resulting from the occlusion of a perfo- 
rating arteriole that is associated with acute neurological symptoms (i.e., lacunar stroke). Lacune refers to a chronic small cavity that presumably represents the healed stage of a lacunar infarct. Note, however, that some lacunes may represent sequelae of a larger infarct or intracerebral hemorrhage (ICH). ${ }^{3}$ Lacunes are often asymptomatic and are commonly found in elderly stroke-free community-dwelling subjects.

Some researchers hypothesized that different lacunar patterns may reflect different underlying SVD etiologies (e.g., microatheroma vs. fibrinoid necrosis) among stroke subjects and compared risk factors among different lacunar patterns. ${ }^{4-6}$ Khan et al. ${ }^{4}$ found that, among SVD patients, isolated lacunar infarct with no or minimal WMH (presumably related to microathero$\mathrm{ma}$ ) was associated with hypercholesterolemia, diabetes, and myocardial infarction, i.e., risk factors similar to large artery disease, while lacunar infarct associated with moderate to severe $\mathrm{WMH}$ (presumably related to fibrinoid necrosis) was associated with age and hypertension. Arauz et al. ${ }^{6}$ found that diabetes, a high hematocrit, and $\mathrm{WMH}$ were related to multiple lacunes (presumably related to fibrinoid necrosis) but not to a single lacunar infarct (presumably related to microatheroma). Nah et al. ${ }^{7}$ found that lacunar infarcts associated with parent atheroma-

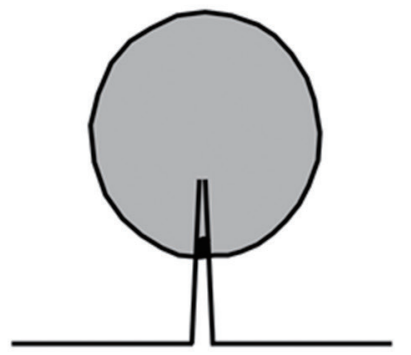

\section{A}

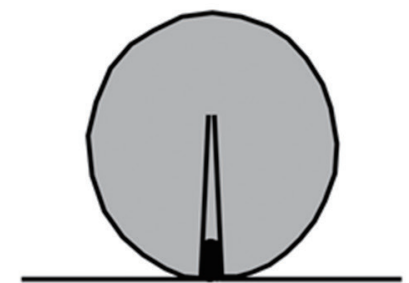

B

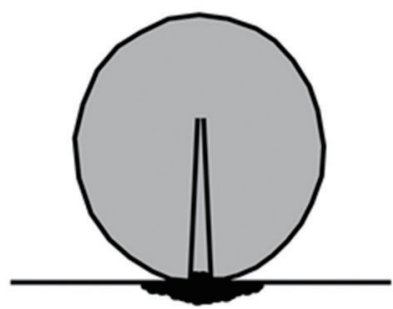

C

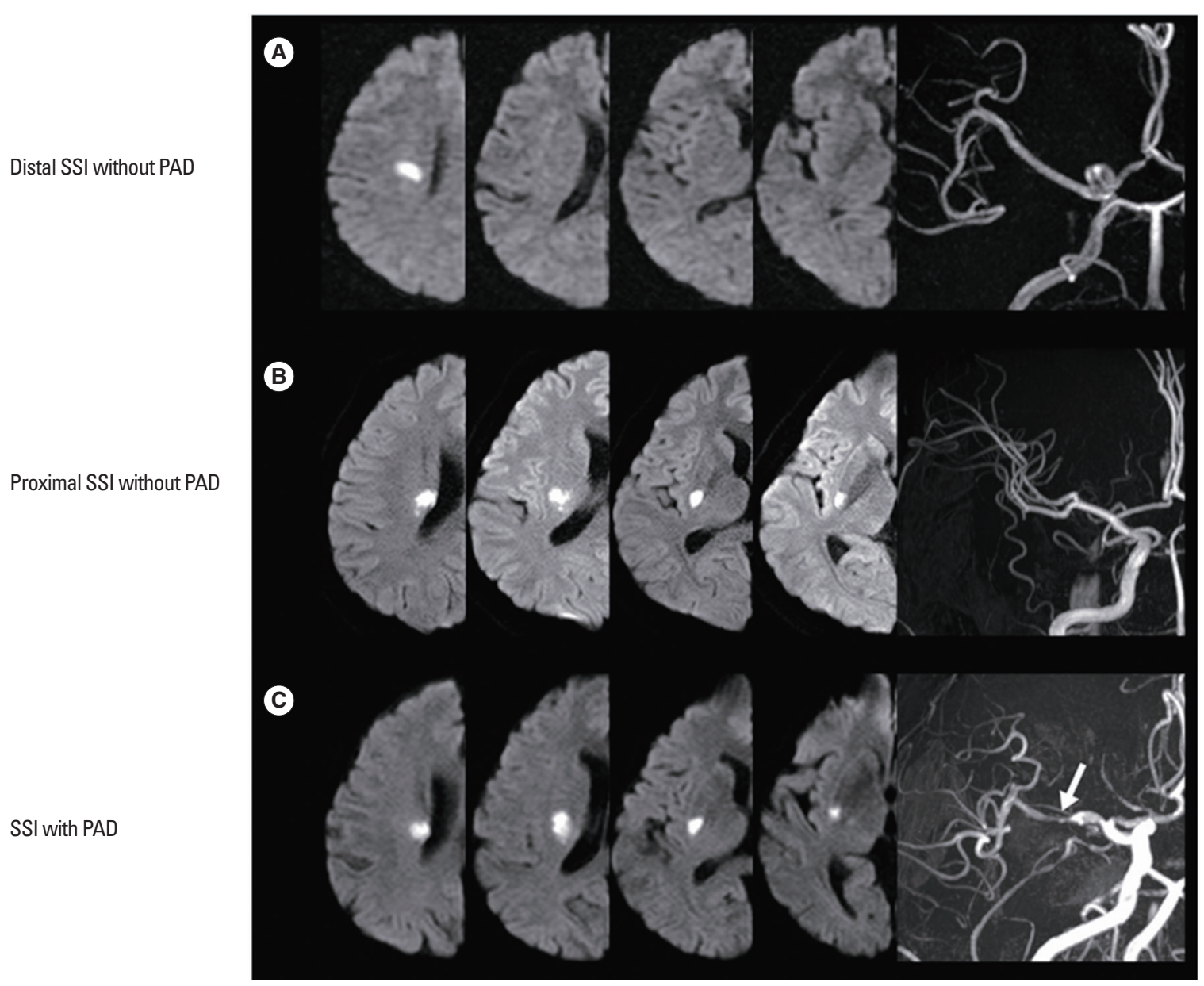

Figure 1. Schematic drawing (upper panels) and clinical examples (lower panels) of the heterogeneous pathogenesis of single subcortical infarction. SSS, single subcortical infarction; PAD, parental artery disease. (modified from Nah et al. ${ }^{7}$ ). 
tous disease (presumably related to a large-vessel atheromatous plaque blocking the mouth of the penetrating artery) had the highest prevalence of atheromatous indicators (i.e., coronary artery disease, asymptomatic cerebral atherosclerotic disease) and the lowest prevalence of SVD indicators (i.e., WMH, CMBs); distal lacunar infarcts without parent atheromatous disease (presumably related to fibrinoid necrosis) had the lowest prevalence of atheromatous indicators and the highest prevalence of SVD indicators; and proximal lacunar infarcts without parent atheromatous disease (presumably related to microatheroma at the proximal portion of the penetrating artery) showed intermediate features (Figure 1).

\section{Risk factors for lacunes}

Overall, asymptomatic lacunes are much more prevalent than lacunar infarcts. In the Cardiovascular Health Study (CHS), of 3,660 community-dwelling elderly individuals, $23 \%$ had one or more lacunes (3-20 mm), most of which were subclinical (89\%). ${ }^{8}$ Factors associated with lacunes were age, diastolic blood pressure (BP), creatinine, pack-years of smoking, internal carotid artery stenosis, male sex, and history of diabetes. A comparison between subgroups of single, multiple, silent, and symptomatic lacunes failed to yield significant differences.

The Atherosclerosis Risk in Communities (ARIC) study ${ }^{9}$ examined the risk factors associated with two SVD subtypes (fibrinoid necrosis and microatheroma). In this cross-sectional study of 1,827 community-dwelling participants, subcortical lesions diagnosed on magnetic resonance imaging (MRI) measuring $\leq 20 \mathrm{~mm}$ in diameter were divided into those $\leq 7 \mathrm{~mm}$ (presumably related to fibrinoid necrosis) and those measuring 8-20 $\mathrm{mm}$ in diameter (presumably related to microatheroma). In this study, smaller lacunes were associated with diabetes and glycated hemoglobin, whereas the larger ones were associated with low-density lipoprotein (LDL) cholesterol. These findings suggest that diabetes may be associated with fibrinoid necrosis and LDL cholesterol with microatheroma. Other factors associated with larger MRI-based lesions were hypertension and smoking.

\section{Risk factors for incident lacunes}

Of 668 elderly community-dwelling participants, the Rotterdam Scan Study (RSS) found that incident lacunes (3-20 mm) were associated with age, female sex, and baseline carotid atherosclerosis. ${ }^{10}$ The Leukoaraiosis And DIsability Study (LADIS) recruited 639 elderly subjects who had at least some degree of WMH on MRI. Incident lacunes (3-10 mm) were associated with WMH load, systolic BP, and low high-density lipoprotein (HDL) cholesterol levels. There were unexpected asso- ciations with high diastolic BP and high LDL cholesterol as factors protecting against incident lacunes. ${ }^{11}$ It is important to note that the definition of lacunes in relation to size and study populations differed between the RSS and LADIS. The latter study included only small lacunes and subjects who already had at least some degree of WMH. Such differences in patients' characteristics may partially explain the disparity between the two studies.

\section{White matter hyperintensities}

WMH of presumed ischemic origin are characterized by demyelination as well as axonal and oligodendrocyte loss with sparing of the U-fibers. Mechanisms explaining WMH may include chronic partial ischemia secondary to diffuse arteriosclerosis, hypotensive episodes (e.g., cardiac arrhythmia, diuretic uses, postural hypotension), ${ }^{12,13}$ breakage of the blood-brain barrier, leakage of toxic fluids into the white matter, ${ }^{14}$ venous collagenosis, ${ }^{15}$ and various combinations thereof. A recent study performed serial MRI in patients with leukoaraiosis for 16 consecutive weeks and found tiny acute ischemic infarcts arising de novo in the cerebral white matter. Over time, the characteristics of these lesions approached those of pre-existing leukoaraiosis, suggesting that silent acute infarcts are also a cause of leukoaraiosis. ${ }^{16}$

Apart from age, most community-based studies have consistently shown that hypertension is associated with WMH. ${ }^{17-21}$ Both the RSS and the Epidemiology of Vascular Ageing study further showed that hypertension duration was associated with $\mathrm{WMH}$, while effective hypertension treatment was associated with lower risk. ${ }^{20,21}$ Noteworthy is that the association between BP levels and confluent WMH may not be linear. Analysis of 10 European cohorts revealed a "J curve" phenomenon in that both increases and decreases in diastolic BP were associated with more severe WMH. ${ }^{22}$ The association between low $\mathrm{BP}$ and WMH is probably related to impaired cerebral autoregulation, which is commonly associated with aging and/or exposure to long-standing vascular risk factors. The RSS found that impaired cerebral vasomotor reactivity was associated with $\mathrm{WMH}{ }^{23}$ As a result of impaired cerebral vasomotor reactivity, the arteries within the brains may fail to dilate to increase cerebral blood flow in response to decreases in systemic BP, resulting in cerebral hemodynamic ischemia. In a recent subgroup analysis of the VITAmins TO Prevent Stroke (VITATOPS) MRI substudy, lower baseline diastolic BP predicted cognitive decline among subjects with severe baseline $\mathrm{WMH}^{24}$ Other studies showed that postural hypoor hypertension, ${ }^{22}$ increasing long-term BP fluctuations, ${ }^{25}$ and various 24-hour ambulatory BP measures (e.g., greater systolic $\mathrm{BP}$ variability, smaller nocturnal decrease in systolic or diastolic 
$\mathrm{BP})^{26}$ were associated with $\mathrm{WMH}$.

Both the RSS and ARIC studies further showed that measures of arterial stiffness (e.g., brachial pulse pressure, aortic pulse wave velocity) were risk factors for WMH even after controlling for BP levels and other cardiovascular risk factors. Thus, it was proposed that arterial stiffening might expose cerebral small vessels to high pulsatile pressure and flow, hence contributing to the pathogenesis of WMH. Most studies found that smoking was associated with WMH. ${ }^{17,19}$ Despite diabetes being a strong risk factor for stroke and coronary heart disease, most communitybased cross-sectional studies failed to find an association between diabetes and WMH. ${ }^{17,18}$ In the Helsinki Aging Brain study, $\mathrm{WMH}$ were associated with diabetes among relatively young ( $<75$ years) subjects but not among older ( $\geq 75$ years) ones. ${ }^{27}$

The RSS found that a high homocysteine level was associated with $\mathrm{WMH} .{ }^{28}$ In a separate study evaluating the association between homocysteine and endothelial markers (ICAM1, thrombomodulin), Hassan et al. ${ }^{29}$ showed that the association between homocysteine and WMH was probably mediated by endothelial activation. The RSS further showed that low vitamin B12 and folate levels, which are closely related to homocysteine metabolism, were associated with WMH independent of homocysteine level..$^{30,31}$ These findings suggest that low vitamin B12 and folate levels may also induce WMH through mechanisms independent of homocysteine or endothelial activation such as low vitamin B12-mediated impairment of myelin integrity. However, it must be noted that the CHS failed to find an association between WMH and homocysteine level. ${ }^{32}$

Findings on the association between cholesterol levels or statin use and WMH are less consistent and sometimes contradictory. The Cardiovascular Risk Factors and the Aging and Incidence of Dementia MRI substudy ${ }^{33}$ showed that use of lipid-lowering drugs was associated with less WMH. The National Heart, Lung, and Blood Institute Twin Study found that a mid-life lower HDL cholesterol level was associated with a later-life WMH. ${ }^{34}$ In contrast, the Austrian Stroke Prevention Study (ASPS) showed that a lower total cholesterol level was associated with $\mathrm{WMH} .{ }^{35}$ In another study investigating association between WMH and cholesterol level among two stroke cohorts (total of 1,135 patients), hyperlipidemia was associated with less WMH. ${ }^{36}$ The authors suggested that hyperlipidemia might play a protective role in cerebral SVD. However, since statin use had high collinearity with hyperlipidemia, the authors could not rule out the possibility that the association between hyperlipidemia and $\mathrm{WMH}$ was related to statin use.

More recent studies evaluating the RNA expression profile in brain or blood samples showed that genes specific for WMH were associated with injury responses, oxidative stress, and in- flammation. ${ }^{37,38}$ In a large genome-wide association study of WMH burden in community-based cohorts of individuals of European descent, a novel locus on chromosome 17 was associated with WMH. Although information on the specific genes and functional variants underlying the reported associations was lacking, further characterization of this locus will provide additional insight into the mechanisms of WMH and hopefully new targets for preventive therapies. ${ }^{39}$

\section{Risk factors for progression of WMH}

Since WMH progression is associated with clinical consequences, $\mathrm{WMH}$ progression may be used as a surrogate marker in preventive trials. Several longitudinal studies with serial MRI investigated the risk factors for WML progression. The majority of studies showed that baseline lesion load, ${ }^{10,11,40}$ older age, ${ }^{10,41}$ smoking, ${ }^{10,42}$ and hypertension ${ }^{10,41,43}$ predicted WMH progression. The ARIC study found that the cumulative mean systolic $\mathrm{BP}$ (i.e., estimated mean systolic BP over the entire period) was a much stronger predictor of WMH progression than was systolic BP obtained at individual time points. ${ }^{44}$ The Three-City-Dijon MRI Study showed that not only baseline hypertension predicted WMH progression among subjects with a high baseline systolic BP $\geq 160 \mathrm{mmHg}$ who were not treated with antihypertensive medication but that antihypertensive treatment started within 2 years was related to a smaller increase in WMH volume than no hypertension treatment. ${ }^{43}$ However, subgroup analyses from the RSS revealed that, among those who already had severe lesions at baseline and those who were very old ( $\geq 80$ years), higher BP did not contribute to lesion progression. ${ }^{10}$ The association between $\mathrm{BP}$ and $\mathrm{WMH}$ progression was stronger in relatively young subjects and in those who did not have severe WMH at baseline. $^{42}$

Most studies did not find an association between baseline diabetes and WMH progression. The association between cholesterol levels and statin use and WMH progression was again controversial. In the CHS, among those with a relatively mild initial WMH burden, increased HDL cholesterol and decreased LDL cholesterol levels were associated with an increased risk of progression; in contrast, among those with a high initial grade, statin use was associated with increased risk. ${ }^{42}$ In the LADIS study, higher triglyceride levels appeared to protect against WMH progression. ${ }^{11}$ In the subgroup analysis of the VITATOPS MRI-substudy, statin use was associated with less progression of WMH and less cognitive decline in subjects with severe $\mathrm{WMH}$ at baseline..$^{24,45}$

In the ASPS, ICAM1 levels were associated with WMH progression, further supporting the causal role of endothelial activation in the pathogenesis of WMH. ${ }^{41}$ In the same study, no asso- 
ciation was found between peripheral markers of coagulation activation (e.g., D-dimer, prothrombin fragments 1 and 2) and $\mathrm{WMH}$ progression. Although the inflammatory process has been postulated as a pathogenic mechanism for $\mathrm{WMH}$, the results from longitudinal studies assessing the association between $\mathrm{C}$-reactive protein levels and $\mathrm{WMH}$ progression were not consistent. The RSS showed a positive association, ${ }^{46}$ whereas the ASPS failed to find an association. ${ }^{47}$

\section{Cerebral microbleeds}

CMBs are small perivascular hemosiderin deposits (usually with macrophages) that presumably result from leakage through cerebral small vessels, which can be visualized as small, rounded, homogeneous, and hypointense lesions on T2*-weighed gradient-recalled echo or susceptibility-weighted imaging MRI. More recent MRI studies suggest that the presence of CMBs is associated with an increased risk of $\mathrm{ICH}^{48}$ and other neurological conditions (e.g., cognitive impairment, gait disturbance, depressive mood) and increased overall mortality. ${ }^{2}$ Deep CMBs are probably associated more with fibrinoid necrosis-related deep ICH, while lobar CMBs correlated more with cerebral amyloid angiopathy (CAA)-related lobar ICH. Both SVD types may exist in the same individual. Since this review focuses on cerebral SVD predominantly associated with vascular risk factors, studies related purely to CAA-associated lobar ICH are not emphasized.

In the systematic review conducted by Cordonnier et al. ${ }^{49}$ hypertension was the most consistent risk factor for CMBs in both healthy adults and those with cerebrovascular diseases. In the same review, diabetes was also associated with CMBs, but such an association was only found among healthy adults. ${ }^{49}$ The RSS found that systolic BP was related to presence of deep/infratentorial CMBs, whereas diastolic BP was related to strictly lobar CMBs. ${ }^{50}$ In the same study, smoking was associated with deep but not lobar CMBs. ${ }^{50}$ In another study of subjects with first-ever lacunar stroke, Staals et al found that ambulatory BP measures (24-hour, day, and night systolic and diastolic BP) were more robust predictors for CMBs than the mere presence or absence of hypertension..$^{51}$ After distinguishing between different locations, various BP characteristics were associated with deep (or combined deep and lobar) CMBs but not with pure lobar CMBs. ${ }^{51}$ In patients with lacunar infarction, Park et al. ${ }^{52}$ found that, after adjustments for other factors, age (odds ratio [OR] 1.07; 95\% confidence interval $[\mathrm{CI}] 1.04-1.11 ; P<0.001)$ and diabetes (OR, 2.17; 95\% CI, 1.04-4.25; $P=0.036$ ) were independently associated with white microangiopathy (predominantly WMH) versus red microangiopathy (predominantly CMBs).

Similar to ICH, low total serum cholesterol levels were associ- ated with CMBs independent of hypertension among subjects having various neurological conditions. ${ }^{53}$ In the RSS, low triglyceride levels rather than $\mathrm{HDL}$ or LDL cholesterol levels were associated with deep/infratentorial CMBs as well as $\mathrm{ICH}^{54}$ Among subjects with previous spontaneous $\mathrm{ICH}$ and statin use, rather than cholesterol levels, was associated with presence and number of CMBs, especially cortico-subcortical CMBs. ${ }^{55}$ However, in a study of patients with acute ischemic stroke or transient ischemic attack, previous statin use was not associated with CMB prevalence or severity. ${ }^{56}$ In another study, proteinuria and homocysteinemia were associated with $\mathrm{CMB}$ presence and severity in patients with ischemic stroke or transient ischemic attack. ${ }^{57}$ In the same study, female sex, history of atrial fibrillation, and SVD stroke subtype were also associated with CMBs.

In the RSS, carriers of the APOE $\varepsilon 4$ and $\varepsilon 2 / \varepsilon 2$ genotype were related to strictly lobar CMBs and not deep/infratentorial CMBs. ${ }^{50}$ In the systematic review and meta-analyses, APOE $\varepsilon 4$ allele carriers are at higher risk of CMBs, particularly in strictly lobar brain locations. ${ }^{58}$ Given the known associations between the APOE genotype with CAA and lobar ICH, the findings support lobar CMBs as an imaging biomarker for CAA.

\section{Risk factors for incident CMBs}

In a small series of patients $(n=21)$ with ischemic stroke or transient ischemic attack, the baseline presence of CMBs and mean systolic BP predicted incident CMBs. ${ }^{59}$ In the RSS, baseline CMBs, age, systolic BP, high pulse pressure, and severe hypertension were all associated with incident $\mathrm{CMB}$. When stratified by location, age, systolic BP, severe hypertension, and low serum cholesterol levels predicted incident deep CMBs, whereas age and those with APOE $\varepsilon 4 / \varepsilon 4$ genotype predicted strictly lobar CMBs. ${ }^{60}$ In another study of subjects attending memory clinics, multiple baseline CMBs, WMH severity, lacunes, and $\mathrm{APOE} \varepsilon 2$ predicted incident CMBs, deep CMBs in particular, whereas smoking was associated with strictly lobar bleeds. ${ }^{61}$

\section{Treatment and secondary prevention}

\section{Thrombolysis}

Intravenous tissue plasminogen activator (t-PA) is the gold standard of treatment of acute ischemic stroke. The efficacy of t-PA is mediated through thrombolysis. However, unlike large artery disease or cardiogenic embolism, the role of the thrombus formation is not considered an important pathomechanism in lacunar infarction. Therefore, the role of t-PA in patients with lacunar infarction has been debated.

The NINDS ${ }^{62}$ and subsequent studies ${ }^{63-66}$ showed that t-PA was not less effective in patients with lacunar stroke than in those 
with non-lacunar stroke. Although a Spanish study ${ }^{66}$ showed that at day 7, patients with lacunar stroke showed the least neurological improvement in terms of absolute National Institutes of Health Stroke Scale (NIHSS) score reduction compared with other stroke subtypes $(P=0.02)$, a recent study using a larger number of patients with lacunar infarction $(n=195)$ showed that the outcomes of these patients were better than those receiving placebo (for modified Rankin scale scores 0-2; relative risk, 1.84; 95\% CI, 1.59-2.13) ${ }^{67}$ Therefore, current consensus and guidelines do not distinguish between ischemic stroke subtypes in terms of t-PA efficacy. ${ }^{68,69}$

Another debate comes from the possibility of an increased risk of hemorrhage in patients with WMH or CMBs. Investigators showed an increased risk of bleeding after thrombolysis in patients with a moderate to high degree of WMH. ${ }^{70-73}$ However, it does not seem to exceed the benefit of t-PA therapy. ${ }^{69}$ More attention has been paid to $\mathrm{CMBs}$ that are considered markers for hemorrhage-prone state. ${ }^{74}$ In the Bleeding Risk Analysis in Stroke Imaging before thrombolysis study, investigators analyzed imaging data acquired within 6 hours after symptom onset in 570 patients with ischemic stroke treated with intravenous t-PA. Baseline T2*-weighted MRI images were evaluated for the presence of CMBs. The primary end point was symptomatic ICH defined as clinical deterioration with an increase in the NIHSS score by $\geq 4$ points temporally related to a parenchymal hematoma (PH) on follow-up-imaging. A total of 242 CMBs were detected in 86 of 570 patients (15.1\%). The proportions of patients with symptomatic ICH were 5.8\% (95\% CI, 1.9-13.0) in the presence of CMBs and 2.7\% (95\% CI, 1.4$4.5)$ in patients without $\mathrm{CMBs}(P=0.170)$, resulting in no significant absolute increase in the risk of ICH (3.1\%; 95\% CI, -2.0-8.3). The data suggested that the increased risk of symptomatic $\mathrm{ICH}$ attributable to $\mathrm{CMBs}$ is small and unlikely to exceed the benefits of thrombolytic therapy. ${ }^{75}$ A meta-analysis of 790 patients revealed the same conclusion. ${ }^{76}$ However, because of the rarity of patients with multiple $\mathrm{CMBs}$, no reliable conclusion was made regarding risk in patients with multiple CMBs.

According to a recent study examining this issue, ${ }^{77}$ among the 326 included patients, 52 (16.0\%) had a single CMB, 19 (5.8\%) had 2-4 CMBs, and 10 (3.1\%) had $\geq 5$ CMBs. The frequency of symptomatic $\mathrm{ICH}(\mathrm{sICH}) / \mathrm{PH}$ was $1.2 \% / 5.7 \%$ in patients without CMBs, $3.8 \% / 3.8 \%$ in patients with a single CMB, $10.5 \%$ / $21.1 \%$ in patients with $2-4 \mathrm{CMBs}$, and $30.0 \% / 30.0 \%$ in patients with $\geq 5 \mathrm{CMBs}$ (for trend, each $P<0.01$ ). The unadjusted OR per additional $\mathrm{CMB}$ for $\mathrm{sICH}$ was 1.19 (95\% confidence interval, 1.07-1.33; $P<0.01$ ) and for $\mathrm{PH}$ was 1.13 (95\% confidence interval, 1.03-1.24; $P=0.01)$. Compared with patients without CMBs, both patients with 2 to $4 \mathrm{CMBs}(P=0.02 / P=0.02)$ and patients with $\geq 5$ CMBs $(P<0.01 / P<0.01)$ had significantly increased $\mathrm{OR}$ for symptomatic ICH and $\mathrm{PH}$, respectively whereas in patients with a single $\mathrm{CMB}$, the OR were not significantly increased $(P=0.21 / P=0.59)$. The results indicated a higher risk of sICH and $\mathrm{PH}$ after intravenous thrombolysis when multiple $\mathrm{CMBs}$ are present with a graded relationship to increasing baseline $\mathrm{CMB}$ number. Therefore, the use of $\mathrm{t}-\mathrm{PA}$ should be cautious in patients with multiple CMBs. Further studies are warranted to evaluate whether the risk of ICH outweighs the benefit of thrombolysis in patients with multiple CMBs.

\section{Risk factor controls}

\section{Hypertension}

Hypertension is the most important risk factor for stroke, and the benefits of lowering BP are apparent in secondary stroke prevention. Pooled analyses showed that long-term BP reduction reduces stroke recurrence by approximately $28 \%{ }^{78-80}$ The Secondary Prevention of Small Subcortical Strokes (SPS3) trial is the unique study to test the target $\mathrm{BP}$ level as secondary prevention in patients with lacunar infarction. The investigators made two systolic BP targets of $130-149 \mathrm{mmHg}$ vs. $<130 \mathrm{mmHg}$ in 3,020 patients with symptomatic lacunar infarction. ${ }^{81}$ After the mean follow-up of 3.7 years, a $19 \%$ non-significant reduction of recurrent stroke was seen in the latter group (hazard ratio [HR], $0.81 ; 95 \% \mathrm{CI}, 0.64-1.03)$. It was noteworthy that ICH was markedly reduced $(63 \%)$ in patients assigned to lower $\mathrm{BP}$ targets (HR, 0.37; CI, 0.15-0.95, $P=0.03){ }^{82}$ The Perindopril Protection against Recurrent Stroke Study MRI-substudy also showed that a more intensive BP-lowering regime might delay WMH progression in stroke patients. ${ }^{83}$

Therefore, it is appropriate to reduce the systolic BP to $<130$ $\mathrm{mmHg}$ in patients with lacunar infarction. There is no evidence to support the usefulness of a particular group of antihypertensives in this condition.

However, the long-term effect of BP reductions remains uncertain, especially in old patients with extensive SVD. According to a long-term cohort study, decreased diastolic BP was associated with decreased gray matter volume and cognitive impairment in older subjects who had hypertension from middle age. This is probably related to cerebral perfusion failure due to a decreased autoregulatory mechanism in patients with longterm hypertension. ${ }^{84}$ Therefore, although a systolic BP reduction to $<130 \mathrm{mmHg}$ is currently recommended in the guidelines, and BP management may have be more cautiously made in patients with advanced age, a long history of hypertension, extensive WMH, or cognitive dysfunction. 


\section{Dyslipidemia}

Dyslipidemia, especially elevated LDL cholesterol levels, plays an important role in the development of atherosclerosis. The Stroke Prevention by Aggressive Reduction in Cholesterol Levels (SPARCL) study is the only to examine the efficacy of high-dose statins for secondary stroke prevention in a large number of patients $(n=4,731)$ with stroke or transient ischemic attack. The results showed that patients who were administered atorvastatin had a significant reduction in stroke (HR, 0.84; 95\% CI, 0.710.99 ) and coronary heart disease (HR, 0.58; 95\% CI, 0.46-9.73). There was a mild but significant increase in hemorrhagic stroke (HR, 5.65; 95\% CI, 2.82-11.30). Because patients with SVD less often have large-artery atherosclerosis but are at an increased risk of bleeding, the efficacy of statins has been questioned in patients with lacunar infarction. However, in the SPARCL trial, 1,409 patients had lacunar infarction, and post-hoc analysis showed that the efficacy of statins was similar in this group. ${ }^{85}$ Although there was an increase in outcomes of hemorrhagic stroke in patients with baseline SVD, the patients also had a reduced outcome of ischemic strokes resulting in a total benefit similar to the overall study cohort. ${ }^{86}$ Therefore, it is recommended that lacunar stroke patients adhere to the current guideline ${ }^{87}$ However, previous studies did not assess WMH or CMBs in detail, so further studies are needed to examine the efficacy of statins in patients with extensive WMH or CMBs. In the Regression of Cerebral Artery Stenosis study, statin use was associated with less WMH progression among those with a severe initial WMH burden ${ }^{88}$ and lower incidence of lacunes in the overall cohort. ${ }^{89}$

\section{Others}

In the recent VITATOPS MRI-substudy, homocysteine lowering using B-vitamins was associated with a reduced WMH volume increment in those with severe baseline SVD (i.e., confluent $\mathrm{WMH}$ and lacunes). ${ }^{90}$ In addition, vitamin $\mathrm{E}$ tocotrienols were recently found to attenuate the progression of WMH among healthy subjects with WMH. ${ }^{91}$

\section{Antiplatelets}

Antiplatelets are generally used in non-cardioembolic stroke. Although studies focusing on lacunar infarction are rare, the benefits of various antiplatelets are considered similar between lacunar and non-lacunar infarction. ${ }^{92-95}$ The SPS3 trial is the only study to focus on lacunar infarction. ${ }^{81}$ Investigators enrolled 3,020 patients with lacunar infarction from North America, South America, and Spain. Patients were allocated to receive aspirin $325 \mathrm{mg}$ plus clopidogrel $75 \mathrm{mg}$ or aspirin $325 \mathrm{mg}$ only. The trial was prematurely stopped due to increased mortality of those assigned to the combination therapy. After the mean fol- low-up of 3.4 years, the annual recurrent stroke rate was $2.5 \%$ in patients on dual therapy versus $2.7 \%$ in those taking aspirin only. The incidence of major hemorrhage in the dual therapy group was significantly $(P<0.001)$ higher $(2.1 \%$ per year $)$ than that in the aspirin monotherapy group $(1.1 \%)$, while mortality was significantly increased in the former group of patients (HR, 1.52; 95\% CI, 1.14-2.04; $P=0.004)$. The authors concluded that, among patients with recent lacunar strokes, the addition of clopidogrel to aspirin does not significantly reduce the risk of recurrent stroke and significantly increases the risk of bleeding and death. Thus, the aspirin and clopidogrel combination should not be used in patients with lacunar infarction unless there are other specific indications. Currently, aspirin, aspirin plus dipyridamole, and clopidogrel are considered acceptable options. ${ }^{87}$

An increased risk of bleeding is the primary concern when antiplatelets are used in stroke patients, especially those with SVD. In this sense, the two drugs cilostazol and triflusal deserve attention. Results from animal ${ }^{96}$ and human ${ }^{97,98}$ studies showed that cilostazol causes fewer bleeding complications than aspirin. Bleeding time- which reflects in vivo physiological hemostasis-was prolonged by aspirin or clopidogrel but not by cilostazol. Moreover, an increase in bleeding time was not observed when cilostazol was co-administered with aspirin or clopidogrel in patients with peripheral arterial disease. ${ }^{99}$ Moreover, cilostazol has an endothelial protective effect and prevents bloodbrain barrier disruption in the ischemic brain. ${ }^{96,100}$ In a murine stroke model, cilostazol was shown to protect microvasculature in the ischemic brain by reducing matrix metalloproteinase- 9 activity. ${ }^{101}$

In the sub-group analysis of the Cilostazol for Prevention of Secondary Stroke study, a significant difference between the cilostazol and aspirin groups was observed with respect to the incidence of hemorrhagic stroke in patients with lacunar stroke. ${ }^{102}$ Therefore, cilostazol seems to be safer than aspirin in terms of the risk of hemorrhagic stroke in hypertensive patients with SVD. ${ }^{102}$ Moreover, as discussed before, arterial stiffening might expose cerebral small vessels to high pulsatile pressure, hence contributing to the pathogenesis of WMH. Cilostazol reportedly decreases cerebral arterial pulsatility in patients with mild $\mathrm{WMH} \cdot{ }^{103}$ Alternatively, triflusal, a drug with an effect similar to that of aspirin but with fewer bleeding complications, ${ }^{104}$ may also be used in patients with a bleeding tendency (e.g., multiple CMBs) SVD patients. Further studies are required to find the appropriate antiplatelets in patients with SVD.

\section{Conclusions and future direction}

Despite extensive studies, many unknown factors of SVD re- 
main. Thrombolysis, antihypertensives, and statins are currently used for the treatment of patients with SVD just as in those with other stroke subtypes. However, it should be remembered that bleeding risk increases in patients with extensive $\mathrm{WMH}$ and CMBs after thrombolysis therapy. Future studies are required to weigh the benefits and risks of thrombolysis in these patients. Based on the SPS 3 trial results, a BP reduction to $<130 \mathrm{mmHg}$ is recommended. However, an excessive BP decrease may induce cognitive decline in older patients with extensive WMH. Future studies are needed to examine the appropriate target BP and cholesterol levels in patients with extensive SVD.

Although the harm of dual antiplatelet therapy (aspirin plus clopidogrel) was correctly identified in patients with SVD, the appropriate antiplatelets in SVD require investigation. In particular, the efficacy of drugs such as cilostazol or triflusal, which are known to be associated with less frequent bleeding complication than aspirin, should be further investigated. Finally, as discussed above, subcortical infarction is heterogeneous. Proximal subcortical infarction, especially those associated with parental artery stenosis, has characteristics of atherosclerosis, whereas distal subcortical infarction has SVD characteristics. In this regard, treatment may have to be tailored; for example, statins and dual antiplatelets may work better in the former group of patients but may be harmful in the latter group. Previous studies disregarded the heterogeneity of small subcortical infarction, so further studies that consider this aspect should be performed.

\section{References}

1. Debette S, Markus HS. The clinical importance of white matter hyperintensities on brain magnetic resonance imaging: Systematic review and meta-analysis. BMJ 2010;341:c3666.

2. Altmann-Schneider I, Trompet S, de Craen AJ, van Es AC, Jukema JW, Stott DJ, et al. Cerebral microbleeds are predictive of mortality in the elderly. Stroke 2011;42:638-644.

3. Wardlaw JM, Smith EE, Biessels GJ, Cordonnier C, Fazekas F, Frayne R, et al. Neuroimaging standards for research into small vessel disease and its contribution to ageing and neurodegeneration. Lancet Neurol 2013;12:822-838.

4. Khan U, Porteous L, Hassan A, Markus HS. Risk factor profile of cerebral small vessel disease and its subtypes. J Neurol Neurosurg Psychiatry 2007;78:702-706.

5. Boiten J, Lodder J, Kessels F. Two clinically distinct lacunar infarct entities? A hypothesis. Stroke 1993;24:652-656.

6. Arauz A, Murillo L, Cantu C, Barinagarrementeria F, Higuera J. Prospective study of single and multiple lacunar infarcts using magnetic resonance imaging: risk factors, recurrence, and outcome in 175 consecutive cases. Stroke 2003;34:2453-2458.
7. Nah HW, Kang DW, Kwon SU, Kim JS. Diversity of single small subcortical infarctions according to infarct location and parent artery disease: analysis of indicators for small vessel disease and atherosclerosis. Stroke 2010;41:2822-2827.

8. Longstreth WT, Jr, Bernick C, Manolio TA, Bryan N, Jungreis CA, Price TR. Lacunar infarcts defined by magnetic resonance imaging of 3660 elderly people: the cardiovascular health study. Arch Neurol 1998;55:1217-1225.

9. Bezerra DC, Sharrett AR, Matsushita K, Gottesman RF, Shibata D, Mosley TH Jr, et al. Risk factors for lacune subtypes in the atherosclerosis risk in communities (aric) study. Neurology 2012;78:102-108.

10. van Dijk EJ, Prins ND, Vrooman HA, Hofman A, Koudstaal PJ, Breteler MM. Progression of cerebral small vessel disease in relation to risk factors and cognitive consequences: Rotterdam Scan study. Stroke 2008;39:2712-2719.

11. Gouw AA, van der Flier WM, Fazekas F, van Straaten EC, Pantoni L, Poggesi A, et al. Progression of white matter hyperintensities and incidence of new lacunes over a 3-year period: the Leukoaraiosis and Disability Study. Stroke 2008;39:1414-1420.

12. McQuinn BA, O'Leary DH. White matter lucencies on computed tomography, subacute arteriosclerotic encephalopathy (binswanger's disease), and blood pressure. Stroke 1987; 18: 900-905.

13. Sulkava R, Erkinjuntti T. Vascular dementia due to cardiac arrhythmias and systemic hypotension. Acta Neurologica Scandinavica 1987;76:123-128.

14. Pantoni L, Inzitari D, Pracucci G, Lolli F, Giordano G, Bracco $\mathrm{L}$, et al. Cerebrospinal fluid proteins in patients with leucoaraiosis: possible abnormalities in blood-brain barrier function. $J$ Neurol Sci 1993;115:125-131.

15. Moody DM, Brown WR, Challa VR, Anderson RL. Periventricular venous collagenosis: association with leukoaraiosis. Radiology 1995;194:469-476.

16. Conklin J, Silver FL, Mikulis DJ, Mandell DM. Are acute infarcts the cause of leukoaraiosis? Brain mapping for 16 consecutive weeks. Ann Neurol 2014;76:899-904.

17. Liao D, Cooper L, Cai J, Toole J, Bryan N, Burke G, et al. The prevalence and severity of white matter lesions, their relationship with age, ethnicity, gender, and cardiovascular disease risk factors: the ARIC study. Neuroepidemiology 1997;16: 149-162.

18. Longstreth WT Jr, Manolio TA, Arnold A, Burke GL, Bryan $\mathrm{N}$, Jungreis $\mathrm{CA}$, et al. Clinical correlates of white matter findings on cranial magnetic resonance imaging of 3301 elderly people. The Cardiovascular Health Study. Stroke 1996;27: 1274-1282.

19. Jeerakathil T, Wolf PA, Beiser A, Massaro J, Seshadri S, 
D'Agostino RB, et al. Stroke risk profile predicts white matter hyperintensity volume: the Framingham Study. Stroke 2004; 35:1857-1861.

20. de Leeuw FE, de Groot JC, Oudkerk M, Witteman JC, Hofman A, van Gijn J, et al. Hypertension and cerebral white matter lesions in a prospective cohort study. Brain 2002;125: 765-772.

21. Dufouil C, de Kersaint-Gilly A, Besancon V, Levy C, Auffray E, Brunnereau L, et al. Longitudinal study of blood pressure and white matter hyperintensities: the EVA MRI cohort. Neurology 2001;56:921-926.

22. van Dijk EJ, Breteler MM, Schmidt R, Berger K, Nilsson LG, Oudkerk $\mathrm{M}$, et al. The association between blood pressure, hypertension, and cerebral white matter lesions: cardiovascular determinants of dementia study. Hypertension 2004;44: 625-630.

23. Bakker SL, de Leeuw FE, de Groot JC, Hofman A, Koudstaal PJ, Breteler MM. Cerebral vasomotor reactivity and cerebral white matter lesions in the elderly. Neurology 1999;52:578-583.

24. Mok V, Xiong Y, Wong KK, Wong A, Schmidt R, Chu WW, et al. Predictors for cognitive decline in patients with confluent white matter hyperintensities. Alzheimers Dement 2012; 8(Suppl):S96-S103.

25. Brickman AM, Reitz C, Luchsinger JA, Manly JJ, Schupf N, Muraskin J, et al. Long-term blood pressure fluctuation and cerebrovascular disease in an elderly cohort. Arch Neurol 2010; 67:564-569.

26. Goldstein IB, Bartzokis G, Hance DB, Shapiro D. Relationship between blood pressure and subcortical lesions in healthy elderly people. Stroke 1998;29:765-772.

27. Ylikoski A, Erkinjuntti T, Raininko R, Sarna S, Sulkava R, Tilvis $\mathrm{R}$. White matter hyperintensities on mri in the neurologically nondiseased elderly. Analysis of cohorts of consecutive subjects aged 55 to 85 years living at home. Stroke 1995;26: 1171-1177.

28. Vermeer SE, van Dijk EJ, Koudstaal PJ, Oudkerk M, Hofman A, Clarke R, et al. Homocysteine, silent brain infarcts, and white matter lesions: The Rotterdam Scan study. Ann Neurol 2002;51:285-289.

29. Hassan A, Hunt BJ, O’Sullivan M, Bell R, D’Souza R, Jeffery $S$, et al. Homocysteine is a risk factor for cerebral small vessel disease, acting via endothelial dysfunction. Brain 2004;127: 212-219.

30. de Lau LM, Smith AD, Refsum H, Johnston C, Breteler MM. Plasma vitamin B12 status and cerebral white-matter lesions. J Neurol Neurosurg Psychiatry 2009;80:149-157.

31. de Lau LM, Refsum H, Smith AD, Johnston C, Breteler MM. Plasma folate concentration and cognitive performance: Rot- terdam scan study. Am J Clin Nutrition 2007;86:728-734.

32. Longstreth WT Jr, Katz R, Olson J, Bernick C, Carr JJ, Malinow MR, et al. Plasma total homocysteine levels and cranial magnetic resonance imaging findings in elderly persons: the cardiovascular health study. Arch Neurol 2004;61:67-72.

33. Vuorinen M, Solomon A, Rovio S, Nieminen L, Kareholt I, Tuomilehto J, et al. Changes in vascular risk factors from midlife to late life and white matter lesions: a 20-year followup study. Dementia Geriatr Cog Disorders 2011;31:119-125.

34. Carmelli D, Swan GE, Reed T, Wolf PA, Miller BL, DeCarli C. Midlife cardiovascular risk factors and brain morphology in identical older male twins. Neurology 1999;52:1119-1124.

35. Schmidt R, Hayn M, Fazekas F, Kapeller P, Esterbauer H. Magnetic resonance imaging white matter hyperintensities in clinically normal elderly individuals. Correlations with plasma concentrations of naturally occurring antioxidants. Stroke 1996;27:2043-2047.

36. Jimenez-Conde J, Biffi A, Rahman R, Kanakis A, Butler C, Sonni $S$, et al. Hyperlipidemia and reduced white matter hyperintensity volume in patients with ischemic stroke. Stroke 2010;41:437-442.

37. Xu H, Stamova B, Jickling G, Tian Y, Zhan X, Ander BP, et al. Distinctive RNA expression profiles in blood associated with white matter hyperintensities in brain. Stroke 2010;41:27442749.

38. Simpson JE, Hosny O, Wharton SB, Heath PR, Holden H, Fernando MS, et al. Microarray rna expression analysis of cerebral white matter lesions reveals changes in multiple functional pathways. Stroke 2009;40:369-375.

39. Fornage M, Debette S, Bis JC, Schmidt H, Ikram MA, Dufouil $\mathrm{C}$, et al. Genome-wide association studies of cerebral white matter lesion burden: the charge consortium. Ann Neurology 2011;69:928-939.

40. Schmidt R, Enzinger C, Ropele S, Schmidt H, Fazekas F. Progression of cerebral white matter lesions: 6-year results of the Austrian Stroke Prevention Study. Lancet 2003;361:2046-2048.

41. Markus HS, Hunt B, Palmer K, Enzinger C, Schmidt H, Schmidt R. Markers of endothelial and hemostatic activation and progression of cerebral white matter hyperintensities: Longitudinal results of the Austrian Stroke Prevention Study. Stroke 2005;36: 1410-1414.

42. Longstreth WT Jr, Arnold AM, Beauchamp NJ Jr, Manolio TA, Lefkowitz D, Jungreis C, et al. Incidence, manifestations, and predictors of worsening white matter on serial cranial magnetic resonance imaging in the elderly: The Cardiovascular Health Study. Stroke 2005;36:56-61.

43. Godin O, Tzourio C, Maillard P, Mazoyer B, Dufouil C. Antihypertensive treatment and change in blood pressure are as- 
sociated with the progression of white matter lesion volumes: The three-city (3c)-dijon magnetic resonance imaging study. Circulation 2011;123:266-273.

44. Gottesman RF, Coresh J, Catellier DJ, Sharrett AR, Rose KM, Coker LH, et al. Blood pressure and white-matter disease progression in a biethnic cohort: atherosclerosis Risk In Communities (ARIC) study. Stroke 2010;41:3-8.

45. Xiong Y, Wong A, Cavalieri M, Schmidt R, Chu WW, Liu X, et al. Prestroke statins, progression of white matter hyperintensities, and cognitive decline in stroke patients with confluent white matter hyperintensities. Neurotherapeutics 2014;11: 606-611.

46. van Dijk EJ, Prins ND, Vermeer SE, Vrooman HA, Hofman A, Koudstaal PJ, et al. C-reactive protein and cerebral smallvessel disease: the Rotterdam Scan study. Circulation 2005; 112:900-905.

47. Schmidt R, Schmidt H, Pichler M, Enzinger C, Petrovic K, Niederkorn K, et al. C-reactive protein, carotid atherosclerosis, and cerebral small-vessel disease: results of the Austrian Stroke Prevention Study. Stroke 2006;37:2910-2916.

48. Wang Z, Soo YO, Mok VC. Cerebral microbleeds: is antithrombotic therapy safe to administer? Stroke 2014;45:2811-2817.

49. Cordonnier C, Al-Shahi Salman R, Wardlaw J. Spontaneous brain microbleeds: systematic review, subgroup analyses and standards for study design and reporting. Brain 2007;130: 1988-2003.

50. Poels MM, Vernooij MW, Ikram MA, Hofman A, Krestin GP, van der Lugt A, et al. Prevalence and risk factors of cerebral microbleeds: an update of the Rotterdam Scan study. Stroke 2010;41:S103-106.

51. Staals J, van Oostenbrugge RJ, Knottnerus IL, Rouhl RP, Henskens LH, Lodder J. Brain microbleeds relate to higher ambulatory blood pressure levels in first-ever lacunar stroke patients. Stroke 2009;40:3264-3268.

52. ParkJH, Ryoo S, Kim SJ, Kim GM, Chung CS, Lee KH, et al. Differential risk factors for lacunar stroke depending on the mri (white and red) subtypes of microangiopathy. PLoS One 2012;7:e44865.

53. Lee SH, Bae HJ, Yoon BW, Kim H, Kim DE, Roh JK. Low concentration of serum total cholesterol is associated with multifocal signal loss lesions on gradient-echo magnetic resonance imaging: analysis of risk factors for multifocal signal loss lesions. Stroke 2002;33:2845-2849.

54. Wieberdink RG, Poels MM, Vernooij MW, Koudstaal PJ, Hofman A, van der Lugt A, et al. Serum lipid levels and the risk of intracerebral hemorrhage: the Rotterdam study. Arterioscler Thromb Vasc Biology 2011;31:2982-2989.

55. Haussen DC, Henninger N, Kumar S, Selim M. Statin use and microbleeds in patients with spontaneous intracerebral hemorrhage. Stroke 2012;43:2677-2681.

56. Day JS, Policeni BA, Smoker WR, Dobre MC, Zhang Y, Leira EC, et al. Previous statin use is not associated with an increased prevalence or degree of gradient-echo lesions in patients with acute ischemic stroke or transient ischemic attack. Stroke 2011;42:354-358.

57. Ovbiagele B, Liebeskind DS, Pineda S, Saver JL. Strong independent correlation of proteinuria with cerebral microbleeds in patients with stroke and transient ischemic attack. Arch Neurol 2010;67:45-50.

58. Maxwell SS, Jackson CA, Paternoster L, Cordonnier C, Thijs V, Al-Shahi Salman R, et al. Genetic associations with brain microbleeds: systematic review and meta-analyses. Neurology 2011;77:158-167.

59. Gregoire SM, Brown MM, Kallis C, Jager HR, Yousry TA, Werring DJ. MRI detection of new microbleeds in patients with ischemic stroke: five-year cohort follow-up study. Stroke 2010;41:184-186.

60. Poels MM, Ikram MA, van der Lugt A, Hofman A, Krestin GP, Breteler MM, et al. Incidence of cerebral microbleeds in the general population: the Rotterdam Scan study. Stroke 2011;42:656-661.

61. Goos JD, Henneman WJ, Sluimer JD, Vrenken H, Sluimer IC, Barkhof F, et al. Incidence of cerebral microbleeds: a longitudinal study in a memory clinic population. Neurology 2010; 74:1954-1960.

62. The National Institute of Neurological Disorders and Stroke rt-PA Stroke Study group. Tissue plasminogen activator for acute ischemic stroke. N Engl J Med 1995;333:1581-1587.

63. Hsia AW, Sachdev HS, Tomlinson J, Hamilton SA, Tong DC. Efficacy of IV tissue plasminogen activator in acute stroke: does stroke subtype really matter? Neurology 2003;61:71-75.

64. Fluri F, Hatz F, Rutgers MP, Georgiadis D, Sekoranja L, Schwegler $\mathrm{G}$, et al. Intravenous thrombolysis in patients with stroke attributable to small artery occlusion. Eur J Neurol 2010;17: 1054-1060.

65. Mustanoja S, Meretoja A, Putaala J, Viitanen V, Curtze S, Atula $S$, et al. Outcome by stroke etiology in patients receiving thrombolytic treatment: Descriptive subtype analysis. Stroke 2011;42:102-106.

66. Fuentes B, Martinez-Sanchez P, Alonso de Lecinana M, Egido J, Reig-Rosello G, Diaz-Otero F, et al. Efficacy of intravenous thrombolysis according to stroke subtypes: the Madrid Stroke Network Data. Eur J Neurol 2012;19:1568-1574.

67. Shobha N, Fang J, Hill MD. Do lacunar strokes benefit from thrombolysis? Evidence from the registry of the Canadian Stroke Network. Int J Stroke 2013;8(Suppl):45-49. 
68. Jauch EC, Saver JL, Adams HP Jr, Bruno A, Connors JJ, Demaerschalk BM, et al. Guidelines for the early management of patients with acute ischemic stroke: a guideline for healthcare professionals from the American Heart Association/American Stroke Association. Stroke 2013;44:870-947.

69. Pantoni L, Fierini F, Poggesi A. Thrombolysis in acute stroke patients with cerebral small vessel disease. Cerebrovasc Dis 2014;37:5-13.

70. Neumann-Haefelin T, Hoelig S, Berkefeld J, Fiehler J, Gass A, Humpich M, et al. Leukoaraiosis is a risk factor for symptomatic intracerebral hemorrhage after thrombolysis for acute stroke. Stroke 2006;37:2463-2466.

71. Palumbo V, Boulanger JM, Hill MD, Inzitari D, Buchan AM. Leukoaraiosis and intracerebral hemorrhage after thrombolysis in acute stroke. Neurology 2007;68:1020-1024.

72. Demchuk AM, Khan F, Hill MD, Barber PA, Silver B, Patel S, et al. Importance of leukoaraiosis on ct for tissue plasminogen activator decision making: evaluation of the NINDS rt-PA Stroke Study. Cerebrovasc Dis 2008;26:120-125.

73. Aries MJ, Uyttenboogaart M, Vroomen PC, De Keyser J, Luijckx GJ. Tpa treatment for acute ischaemic stroke in patients with leukoaraiosis. Eur J Neurol 2010;17:866-870.

74. Chalela JA, Kang DW, Warach S. Multiple cerebral microbleeds: mri marker of a diffuse hemorrhage-prone state. $J$ Neuroimaging 2004; 14:54-57.

75. Fiehler J, Albers GW, Boulanger JM, Derex L, Gass A, Hjort $\mathrm{N}$, et al. Bleeding risk analysis in stroke imaging before thrombolysis (brasil): pooled analysis of T2*-weighted magnetic resonance imaging data from 570 patients. Stroke 2007;38: 2738-2744.

76. Charidimou A, Kakar P, Fox Z, Werring DJ. Cerebral microbleeds and the risk of intracerebral haemorrhage after thrombolysis for acute ischaemic stroke: systematic review and meta-analysis. J Neurol Neurosurg Psychiatry 2013;84:277-280.

77. Dannenberg S, Scheitz JF, Rozanski M, Erdur H, Brunecker $\mathrm{P}$, Werring DJ, et al. Number of cerebral microbleeds and risk of intracerebral hemorrhage after intravenous thrombolysis. Stroke 2014;45:2900-2905.

78. Progress Management Committee. PROGRESS-Perindopril protection Against Recurrent Stroke Study: characteristics of the study population at baseline. J Hypertens 1999;17:1647-1655.

79. Gueyffier F, Boissel JP, Boutitie F, Pocock S, Coope J, Cutler $\mathrm{J}$, et al. Effect of antihypertensive treatment in patients having already suffered from stroke. Gathering the evidence. The INDANA (INdividual dData ANalysis of Antihypertensive intervention trials) project collaborators. Stroke 1997;28: 2557-2562.

80. Rashid P, Leonardi-Bee J, Bath P. Blood pressure reduction and secondary prevention of stroke and other vascular events: a systematic review. Stroke 2003;34:2741-2748.

81. Benavente OR, Hart RG, McClure LA, Szychowski JM, Coffey CS, Pearce LA. Effects of clopidogrel added to aspirin in patients with recent lacunar stroke. N Engl J Med 2012;367: 817-825.

82. Benavente OR, Coffey CS, Conwit R, Hart RG, McClure LA, Pearce LA, et al. Blood-pressure targets in patients with recent lacunar stroke: the SPS3 randomised trial. Lancet 2013;382: 507-515.

83. Dufouil C, Chalmers J, Coskun O, Besancon V, Bousser MG, Guillon P, et al. Effects of blood pressure lowering on cerebral white matter hyperintensities in patients with stroke: the PROGRESS (Perindopril pROtection aGainst REcurrent Stroke Study) magnetic resonance imaging substudy. Circulation. 2005;112:1644-1650.

84. Muller M, Sigurdsson S, Kjartansson O, Aspelund T, Lopez OL, Jonnson PV, et al. Joint effect of mid- and late-life blood pressure on the brain: the Ages-Reykjavik study. Neurology 2014;82:2187-2195.

85. Amarenco P, Benavente O, Goldstein LB, Callahan A 3rd, Sillesen $\mathrm{H}$, Hennerici MG, et al. Results of the stroke prevention by aggressive reduction in cholesterol levels (SPARCL) trial by stroke subtypes. Stroke 2009;40:1405-1409.

86. Goldstein LB, Amarenco P, Szarek M, Callahan A 3rd, Hennerici M, Sillesen $\mathrm{H}$, et al. Hemorrhagic stroke in the stroke prevention by aggressive reduction in cholesterol levels study. Neurology 2008;70:2364-2370.

87. Furie KL, Kasner SE, Adams RJ, Albers GW, Bush RL, Fagan $\mathrm{SC}$, et al. Guidelines for the prevention of stroke in patients with stroke or transient ischemic attack: A guideline for healthcare professionals from the American Heart Association/ American Stroke Association. Stroke 2011;42:227-276.

88. Mok VC, Lam WW, Fan YH, Wong A, Ng PW, Tsoi TH, et al. Effects of statins on the progression of cerebral white matter lesion: post hoc analysis of the ROCAS (Regression Of Cerebral Artery Stenosis) study. J Neurol 2009;256:750-757.

89. Fu JH, Mok V, Lam W, Wong A, Chu W, Xiong Y, et al. Effects of statins on progression of subclinical brain infarct. Cerebrovasc Dis 2010;30:51-56.

90. Cavalieri M, Schmidt R, Chen C, Mok V, de Freitas GR, Song $\mathrm{S}$, et al. $\mathrm{B}$ vitamins and magnetic resonance imaging-detected ischemic brain lesions in patients with recent transient ischemic attack or stroke: the VITAmins TO Prevent Stroke (VITATOPS) MRI-substudy. Stroke 2012;43:3266-3270.

91. Gopalan Y, Shuaib IL, Magosso E, Ansari MA, Abu Bakar MR, Wong JW, et al. Clinical investigation of the protective effects of palm vitamin $\mathrm{E}$ tocotrienols on brain white matter. 
Stroke 2014;45:1422-1428.

92. Bousser MG, Eschwege E, Haguenau M, Lefaucconnier JM, Thibult N, Touboul D, et al. "AICLA" controlled trial of aspirin and dipyridamole in the secondary prevention of atherothrombotic cerebral ischemia. Stroke 1983;14:5-14.

93. Gent M, Blakely JA, Easton JD, Ellis DJ, Hachinski VC, Harbison JW, et al. The Canadian American Ticlopidine Study (CATS) in thromboembolic stroke. Lancet 1989;1:1215-1220.

94. Gorelick PB, Richardson D, Kelly M, Ruland S, Hung E, Harris $\mathrm{Y}$, et al. Aspirin and ticlopidine for prevention of recurrent stroke in black patients: A randomized trial. JAMA 2003; 289:2947-2957.

95. Halkes PH, van Gijn J, Kappelle LJ, Koudstaal PJ, Algra A. Aspirin plus dipyridamole versus aspirin alone after cerebral ischaemia of arterial origin (ESPRIT): randomised controlled trial. Lancet 2006;367:1665-1673.

96. Nonaka Y, Tsuruma K, Shimazawa M, Yoshimura S, Iwama T, Hara $\mathrm{H}$. Cilostazol protects against hemorrhagic transformation in mice transient focal cerebral ischemia-induced brain damage. Neurosci Lett 2009;452:156-161.

97. Huang Y, Cheng Y, Wu J, Li Y, Xu E, Hong Z, et al. Cilostazol as an alternative to aspirin after ischaemic stroke: a randomised, double-blind, pilot study. Lancet Neurol 2008;7:494-499.

98. Shinohara Y, Katayama Y, Uchiyama S, Yamaguchi T, Handa S, Matsuoka K, et al. Cilostazol for Prevention of Secondary Stroke (CSPS2): an aspirin-controlled, double-blind, randomised non-inferiority trial. Lancet Neurol 2010;9:959-968.
99. Wilhite DB, Comerota AJ, Schmieder FA, Throm RC, Gaughan JP, Rao AK. Managing pad with multiple platelet inhibitors: the effect of combination therapy on bleeding time.J Vasc Surg 2003;38:710-713.

100. Lee JH, Kim KY, Lee YK, Park SY, Kim CD, Lee WS, et al. Cilostazol prevents focal cerebral ischemic injury by enhancing casein kinase 2 phosphorylation and suppression of phosphatase and tensin homolog deleted from chromosome 10 phosphorylation in rats. J Pharmacol Exp Ther 2004;308:896-903.

101. Kasahara Y, Nakagomi T, Matsuyama T, Stern D, Taguchi A. Cilostazol reduces the risk of hemorrhagic infarction after administration of tissue-type plasminogen activator in a murine stroke model. Stroke 2012;43:499-506.

102. Uchiyama S, Shinohara Y, Katayama Y, Yamaguchi T, Handa S, Matsuoka K, et al. Benefit of cilostazol in patients with high risk of bleeding: subanalysis of cilostazol stroke prevention study 2. Cerebrovasc Dis 2014;37:296-303.

103. Han SW, Song TJ, Bushnell CD, Lee SS, Kim SH, Lee JH, et al. Cilostazol decreases cerebral arterial pulsatility in patients with mild white matter hyperintensities: subgroup analysis from the effect of cilostazol in acute lacunar infarction based on pulsatility index of transcranial doppler (ECLIPse) study. Cerebrovasc Dis 2014;38:197-203.

104. Culebras A, Rotta-Escalante R, Vila J, Dominguez R, Abiusi G, Famulari A, et al. Triflusal vs aspirin for prevention of cerebral infarction: a randomized stroke study. Neurology 2004; 62:1073-1080. 